\title{
C-reactive protein is not a useful indicator for infection in surgical intensive care units
}

\author{
Proteína C-reativa não é um marcador útil de infecção em unidade de terapia \\ intensiva cirúrgica
}

\author{
Domingos Dias Cicarelli', Joaquim Edson Vieira", Fábio Ely Martins Benseñor"
}

Surgical Intensive Care Unit, Anesthesia Division, Department of Surgery, Hospital das Clínicas (HC), Faculdade de Medicina da Universidade de São Paulo (FMUSP), São Paulo, Brazil

\section{KEY WORDS:}

Shock, septic.

C-reactive protein.

Systemic inflammatory response

syndrome.

Multiple organ failure.

Lactates.

\section{PALAVRAS-CHAVE:}

Choque séptico.

Proteína C-reativa.

Síndrome de resposta inflamatória sistêmica.

Insuficiência de múltiplos órgãos. Lactatos.

\begin{abstract}
CONTEXT AND OBJECTIVE: C-reactive protein (CRP) is commonly used as a marker for inflammatory states and for early identification of infection. This study aimed to investigate CRP as a marker for infection in patients with postoperative septic shock.

DESIGN AND SETTING: Prospective, single-center study, developed in a surgical intensive care unit at Hospital das Clínicas, Faculdade de Medicina da Universidade de São Paulo.

METHODS: This study evaluated 54 patients in the postoperative period, of whom 29 had septic shock (SS group) and 25 had systemic inflammatory response syndrome (SIRS group). All of the patients were monitored over a seven-day period using the Sequential Organ Failure Assessment (SOFA) score and daily CRP and lactate measurements.

RESULTS: The daily CRP measurements did not differ between the groups. There was no correlation between CRP and lactate levels and the SOFA Score in the groups. We observed that the plasma CRP concentrations were high in almost all of the patients. The patients presented an inflammatory state postoperatively in response to surgical aggression. This could explain the elevated CRP measurements, regardless of whether the patient was infected or not.

CONCLUSIONS: This study did not show any correlation between CRP and infection among patients with SIRS and septic shock during the early postoperative period.
\end{abstract}

\section{RESUMO}

CONTEXTO E OBJETIVO: A proteína C reativa (PCR) é muito usada como marcador de estados inflamatórios e na identificação precoce de infecção. Este estudo teve como proposta investigar a PCR como marcadora de infecção em pacientes em choque séptico no período pós-operatório.

TIPO DE ESTUDO E LOCAL: Estudo prospectivo, monocêntrico, desenvolvido numa unidade de terapia intensiva pós-operatória do Hospital das Clínicas da Faculdade de Medicina da Universidade de São Paulo.

MÉTODOS: Foram avaliados 54 pacientes no pós-operatório, sendo 29 deles com choque séptico (grupo SS) e 25 com síndrome da resposta inflamatória sistêmica (grupo SI). Todos os pacientes foram acompanhados durante sete dias pelo escore SOFA (Sequential Organ Failure Assessment) e com dosagens diárias de PCR e lactato.

RESULTADOS: As dosagens de PCR não diferiram entre os grupos. Não foi observada correlação entre dosagem de PCR e lactato ou escore SOFA nos grupos estudados. Observamos que as concentrações plasmáticas de PCR estavam elevadas em quase todos os pacientes avaliados. Os pacientes no pós-operatório apresentam estado inflamatório em resposta à agressão cirúrgica, sendo este fato capaz de explicar as dosagens de PCR elevadas, independentemente de o paciente estar ou não infectado.

CONCLUSÕES: Este estudo não evidenciou correlação entre PCR e infecção nos pacientes com síndrome da resposta inflamatória sistêmica e choque séptico no período pós-operatório precoce.
IMD, PhD. Attending anesthesiologist, Intensive Care Unit, Anesthesia Division, Department of Surgery, Hospital das Clínicas da Faculdade (HC), Faculdade de Medicina da Universidade de São Paulo (FMUSP), São Paulo, Brazil.

"MD, PhD. Attending anesthesiologist, Anesthesia Division, Department of Surgery, Hospital das Clínicas (HC), Faculdade de Medicina da Universidade de São Paulo (FMUSP), São Paulo, Brazil. 


\section{INTRODUCTION}

Systemic inflammatory response syndrome (SIRS) is a common event among critically ill patients. Whether accompanied by infection or not, it is frequent postoperatively, particularly in relation to trauma, burns, pancreatitis or pulmonary diseases. ${ }^{1}$ Conversely, severe sepsis and septic shock are states of systemic inflammation in response to infectious agents that may lead to multiple organ system failure, and these are a frequent cause of postoperative mortality in intensive care units (ICUs). ${ }^{2}$

The release of inflammatory response mediators over the course of such diseases gives physicians a useful tool for marking the severity of sepsis. ${ }^{3}$ One of these markers, C-reactive protein (CRP), is produced by the liver in response to tissue injury or infection. It reaches its maximum serum concentration around 24 hours after the inflammatory process sets in and slowly decreases thereafter. ${ }^{4}$ Previous studies have presented doubtful conclusions regarding the efficiency of CRP for differentiating infection from inflammation, especially during the postoperative period. ${ }^{5,6}$

\section{OBJECTIVE}

Considering the importance of distinguishing inflammatory septic response from non-infective events, this study had the aim of evaluating the role of CRP as a marker for infection in critically ill patients during the postoperative period.

\section{METHODS}

This prospective study was performed in the surgical ICU at Hospital das Clínicas (HC), Faculdade de Medicina de São Paulo (FMUSP). After approval by the local ethics committee, patients admitted to the ICU with a diagnosis of SIRS or septic shock (SS) in accordance with the definitions of the American College of Chest Physicians/Society of Critical Care Medicine Consensus Conference were included. ${ }^{7}$ Informed consent was obtained from the patients or from their next of kin. ${ }^{8}$ Patients under 18 years of age were excluded.

At the time when patients were admitted into the study, their severity of illness was assessed according to the Acute Physiology And Chronic Health Evaluation II score (APACHE II). ${ }^{9}$ They were also assessed daily by using the Sequential Organ Failure Assessment score (SOFA) for seven consecutive days or until their discharge from the ICU, if this occurred earlier. ${ }^{10,11}$ C-reactive protein was measured on a daily basis.

For infection to be diagnosed, clinical signs of SIRS and a defined source of microbiologically confirmed infection (surgical finding) or positive blood, urine, catheter tip or tracheal secretion cultures had to be present. ${ }^{5}$

The patients received conventional therapy regarding antibiotic regimens, serial blood cultures and discharge criteria. The relevant clinical and laboratory tests were conducted daily throughout the study.

Blood samples for CRP measurements were thawed and assayed in batches in an automated analyzer (Behring Nephelometer Analyzer
II, Dade Behring, Marburg, Denmark) for particle-enhanced immunonephelometry using commercial kits. The analytical sensitivity and accuracy of the CRP assays was $0.0175 \mathrm{mg} / \mathrm{l}$ (coefficient of variation, $\mathrm{CV}=7.6 \%)$.

Statistical analysis to evaluate changes in variables over the course of the ICU stay was performed by means of two-way analysis of variance (ANOVA). Student's t-test was used to analyze differences between groups. $\mathrm{P}<0.05$ was considered significant. The sample size was calculated as 25 patients per group, based on the standard normal deviation for $\alpha=0.05$ and $\beta=0.20 .^{12}$

\section{RESULTS}

Out of the 59 patients enrolled, 29 formed the SS group and 25 formed the SIRS group. Five patients were excluded after their next of kin withdrew their signed consent. The patients' characteristics at the time of admission to the study, their prior or preexisting conditions, the type of surgery and the outcome data are presented in Table 1. The microbiological characteristics of both groups are presented in Table 2. The evolution of SOFA scores in the two groups is presented in Figure 1. The daily evolution of CRP in the two groups is presented in Figure 2. Serum lactate was different between groups, as shown in Figure 3.

There was no correlation between CRP and SOFA in either group $(r=0.004 ; P=0.99)$. There was a positive correlation between CRP and lactate in both groups, but without statistical significance $(r=0.60$; $\mathrm{P}=0.15)$.

The daily evolution of CRP plasma concentrations among patients who died and survivors is presented in Figure 4. The mortality rate over seven days was 38\% for the SS group (11 out of 29 patients) and $24 \%$ for the SIRS group (six out of 25 patients) $(\mathrm{P}=0.28)$. Over 28 days, the

Table 1. Patient characteristics in the two groups, at the time of admission to the study

\begin{tabular}{|c|c|c|c|}
\hline Group & SS & SIRS & $\mathrm{P}$ \\
\hline Characteristics & $\mathrm{n}=29$ & $\mathrm{n}=25$ & \\
\hline Age (years) & $59.4 \pm 16.4$ & $57.2 \pm 19.1$ & NS \\
\hline Male sex & $55 \%$ & $56 \%$ & NS \\
\hline Weight (kg) & $67.5 \pm 13$ & $67.3 \pm 10.8$ & NS \\
\hline APACHE II score & $19 \pm 5$ & $16 \pm 5$ & 0.02 \\
\hline SOFA score & $8.4 \pm 3.7$ & $8.1 \pm 4.4$ & 0.01 \\
\hline Preexisting conditions & $\mathrm{n}(\%)$ & $\mathrm{n}(\%)$ & \\
\hline Hypertension & $10(34)$ & $7(28)$ & NS \\
\hline Myocardial infarction & $5(17)$ & $3(12)$ & NS \\
\hline Diabetes & $4(14)$ & $4(16)$ & NS \\
\hline Liver disease & $3(10)$ & $1(4)$ & NS \\
\hline COPD & $2(7)$ & $2(8)$ & NS \\
\hline Cancer & $6(21)$ & $5(20)$ & NS \\
\hline \multicolumn{4}{|l|}{ Surgery } \\
\hline Multiple trauma (excluding head trauma) & $1(3.4)$ & $1(4)$ & NS \\
\hline Gastrointestinal surgery & $21(72)$ & $15(60)$ & NS \\
\hline Abdominal aneurysm repair & $2(7)$ & $2(8)$ & NS \\
\hline Thoracic surgery & $1(3.4)$ & $1(4)$ & NS \\
\hline Urologic surgery & $3(10)$ & $2(8)$ & NS \\
\hline Other indicators of severity (days) & Mean \pm SD & Mean \pm SD & \\
\hline Mechanical ventilation & $4.4 \pm 2.6$ & $3.2 \pm 2.3$ & NS \\
\hline Shock (use of vasopressor) & $3.7 \pm 2.4$ & $2.3 \pm 2.2$ & 0.03 \\
\hline
\end{tabular}

SS = group with septic shock; SIRS = group with systemic inflammatory response syndrome; APACHE = acute physiology and chronic health evaluation; SOFA = sequential organ failure assessment; COPD = chronic obstructive pulmonary disease; $\mathrm{NS}=$ not statistically significant; $\mathrm{SD}=$ standard deviation 
Table 2. Microbiological analysis on patients in the two groups, including surgical procedure performed, antibiotic therapy, etiological infectious agent and source from which the agent was isolated

\begin{tabular}{|c|c|c|c|c|}
\hline Patient & Surgery/pathological condition & Antibiotics & Type of organism & Type of culture \\
\hline 1-SS & Cholecystectomy/biliary abscess & Vancomycin + cefepime & S. aureus & Abscess culture \\
\hline 2-SS & Empyema pleural drainage & Ceftriaxone + clindamycin & S. pyogenes & Pleural abscess culture \\
\hline 3-SS & Cholecystectomy/biliary abscess & Ceftriaxone + metronidazole & - & Negative cultures \\
\hline 4-SS & Cystectomy/pyuria & Ceftriaxone + metronidazole & - & Negative cultures \\
\hline 5 -SS & Abdominal aneurysm repair & Ceftazidime + clindamycin & $P$. aeruginosa & Blood culture \\
\hline $6-S S$ & Colectomy/cavity contamination & Ceftriaxone + metronidazole & - & Negative cultures \\
\hline 7-SS & Calcaneal exposure fracture & Ciprofloxacin & E. faecalis & Surgical site culture \\
\hline 8-SS & Pyonephrosis drainage & Ceftriaxone & K. pneumoniae & Urinary culture \\
\hline 9-SS & Sigmoidectomy & Ceftriaxone + metronidazole & A. baumanii & Blood culture \\
\hline $10-S S$ & Hemicolectomy & Ceftriaxone + metronidazole & Candida albicans & Blood culture \\
\hline $11-S S$ & Enterectomy/mesenteric ischemia & Ceftriaxone + metronidazole & - & Negative cultures \\
\hline $12-S S$ & Pancreatic-duodenal resection & Ceftriaxone & Serratia marcesens & BAL \\
\hline 13-SS & Pancreatic-duodenal resection & Ceftriaxone + metronidazole & S. coag negative & Blood culture \\
\hline 14-SS & Retroperitoneal abscess drainage & Cefepime + vancomycin + imipenem & $P$. aeruginosa & Blood culture \\
\hline 15-SS & Abdominal aneurysm repair & Vancomycin + imipenem & S. aureus & Blood culture \\
\hline $16-S S$ & Sigmoidectomy/perforative lesion & Ceftriaxone + metronidazole & Serratia marcesens & Ascites culture \\
\hline $17-S S$ & Colectomy & Cefepime + vancomycin & S. aureus & Blood culture \\
\hline 18-SS & Gastric ulcer & Ceftriaxone + metronidazole & - & Negative cultures \\
\hline 19-SS & Cholecystectomy & Ciprofloxacin + metronidazole & Escherichia coli & Urinary culture \\
\hline 20-SS & Hemicolectomy & Cefepime + vancomycin + metronidazole & E. cloacae & Blood culture \\
\hline 21-SS & Enterectomy/cavity contamination & Vancomycin + imipenem & - & Negative cultures \\
\hline 22-SS & Colectomy & Ceftriaxone + metronidazole & A. baumanii & Blood culture \\
\hline 23-SS & Colectomy & Ceftriaxone + metronidazole & $P$. aeruginosa & Blood culture \\
\hline 24-SS & Enterectomy/cavity contamination & Ceftriaxone + metronidazole & - & Negative cultures \\
\hline 25-SS & Cervical abscess drainage & Imipenem + vancomycin + metronidazole & K. pneumoniae & Blood culture \\
\hline 26-SS & Sigmoidectomy/perforative lesion & Ceftriaxone + metronidazole & P. aeruginosa & Blood culture \\
\hline 27-SS & Sigmoidectomy & Cefepime + metronidazole & S. aureus & Blood culture \\
\hline 28-SS & Pyonephrosis drainage & Cefepime + metronidazole & - & Negative cultures \\
\hline 29-SS & Colectomy & Ceftriaxone + metronidazole & $P$. aeruginosa & BAL \\
\hline 1-SIRS & Pancreatic-duodenal resection & Cephalothin & - & Blood culture \\
\hline 2-SIRS & Aortic-iliac bypass & Clindamycin & - & Blood culture \\
\hline 3-SIRS & Hemicolectomy & Cefoxitin & - & - \\
\hline 4-SIRS & Nephrectomy & Cephalotin & - & Blood and urinary \\
\hline 5-SIRS & Gastric resection & Cefoxitin & - & Blood culture \\
\hline 6 -SIRS & Femoral exposure fracture & Clindamycin + gentamicin & - & Surgical site culture \\
\hline 7-SIRS & Abdominal aneurysm repair & Cephalothin & - & Blood and urinary \\
\hline 8-SIRS & Appendectomy & Cephalothin & - & Blood culture \\
\hline 9-SIRS & Hemicolectomy & Cefoxitin & - & Blood and urinary \\
\hline 10-SIRS & Prostatectomy & Cefazolin & - & Blood culture \\
\hline 11-SIRS & Colectomy & Cefoxitin & - & - \\
\hline 12-SIRS & Iliac endarterectomy & Cefazolin & - & Blood and urinary \\
\hline 13-SIRS & Colectomy & Cefoxitin & - & Blood culture \\
\hline 14-SIRS & Cholecystectomy & Cefazolin & - & - \\
\hline 15-SIRS & Colectomy & Cefoxitin & - & Blood culture \\
\hline 16-SIRS & Cholecystectomy & Cephalothin & - & - \\
\hline 17-SIRS & Hemicolectomy & Cefoxitin & - & Blood and urinary \\
\hline 18-SIRS & Lobectomy & Cefazolin & - & Blood culture \\
\hline 19-SIRS & Sigmoidectomy & Ceftriaxone + metronidazole & - & Blood culture \\
\hline 20-SIRS & Ulnar exposure fracture & Clindamycin + gentamicin & - & Surgical site culture \\
\hline 21-SIRS & Femoral exposure fracture & Clindamycin + gentamicin & - & Surgical site culture \\
\hline 22-SIRS & Splenectomy & Cefazolin & - & - \\
\hline 23-SIRS & Abdominal aneurysm repair & Cefazolin & - & Blood and urinary \\
\hline 24-SIRS & Enterectomy & Cefoxitin & - & Blood culture \\
\hline 25-SIRS & Cholecystectomy & Cefazolin & - & Blood culture \\
\hline
\end{tabular}

SS = group with septic shock; SIRS = group with systemic inflammatory response syndrome; . aureus = Staphylococcus aureus, S. pyogenes = Streptococcus pyogenes, $P$. aeruginosa = Pseudomonas aeruginosa, E. faecalis Enterobacter faecalis, K. pneumoniae = Klebsiella pneumoniae, . baumanii $=$ Acinetobacter baumanii, $\mathrm{S}$. coag negative = Staphylococcus coagulase negative; $E$. cloacae $=$ Enterobacter cloacae; $\mathrm{BAL}=$ bronchoalveolar lavage. 
mortality rates in the SS and SIRS groups were, respectively, 62\% (18 out of 29$)$ and $44 \%$ (11 out of 25$)(\mathrm{P}=0.17)$. The $\mathrm{SS}$ group presented a seven-day relative risk (RR) of mortality of 1.6 (95\% confidence interval, CI: 0.99-2.59), in comparison with the SIRS group; the 28-day relative risk of mortality was 1.4 (95\% CI: 0.83-2.35).

\section{DISCUSSION}

The present study did not show any correlation between CRP and diagnoses of infection among postoperative patients with SIRS and septic shock. Nor did the SOFA score correlate with CRP measurements.

The patterns of cytokine production differ for different inflammatory conditions, as does the acute-phase response. Acute-phase changes reflect the presence and intensity of inflammation. Therefore, they have been used as a clinical guide for diagnosis and care. Conversely, serum CRP has been widely used as a marker for inflammation and tissue injury, as well as for diagnostic purposes, thereby differentiating inflammatory and infectious diseases. ${ }^{13}$ Previous reports have taken the view that elevated CRP levels are also associated with adverse outcomes in healthy individuals, as well as in patients with stable angina or acute coronary syndromes. ${ }^{14}$

Among patients with plasma CRP concentrations higher than $10 \mathrm{mg} / \mathrm{dl}, 80$ to $85 \%$ have bacterial infections, according to previous studies. ${ }^{15,16}$ In this present study, patients from both groups presented plasma CRP concentrations higher than $10 \mathrm{mg} / \mathrm{dl}$ during the seven-day observation period, but no difference between septic shock (infected) and SIRS (non-infected) patients was found, thus contrasting with the results of Gabay et al. ${ }^{16}$ It is important to stress that Meisner et al. observed that CRP plasma concentrations were postoperatively elevated in almost all patients, regardless of the type of surgery. ${ }^{6}$ Suprin et al. observed that CRP was not a valuable indicator of infection in a medical ICU, due to its poor sensitivity and specificity. ${ }^{15}$ Ugarte et al. reported that CRP levels were not much higher in infected patients with shock, ${ }^{17}$ and this was confirmed by the findings presented here. All the patients studied were in the postoperative period. This fact, also according to Meisner, could in itself explain the elevated CRP measurements observed, regardless of whether infection was present or not. Hence, CRP cannot be used as a marker for infection in the early postoperative period.

Higher CRP levels were observed among the patients in the SIRS group than among those in the SS group. This can be explained by the antibiotic regimens among the septic shock patients. Many patients with SIRS received only prophylactic antibiotic therapy, while septic shock patients received antibiotics during their entire ICU stay. Given that Ventetuolo et al. reported that CRP might be used to follow the response to antibiotic therapy, ${ }^{18}$ the septic patients' response to the antibiotic regimen could be the reason for their lower CRP levels.

The difference in CRP concentrations between patients who survived and those who did not agrees with previous reports in which this protein was considered to be a valuable prognostic marker for death among patients with septic shock. .,10 $^{-10}$

A previous report associated CRP levels and organ failure among critically ill patients, although these patients were not specifically un- der septic shock. ${ }^{10}$ It considered that CRP was a good marker for organ dysfunction after septic shock had been diagnosed. However, disagreeing with that report, the results presented here, as well as in previously published results, ${ }^{19,20}$ did not establish any positive correlation between CRP and SOFA.

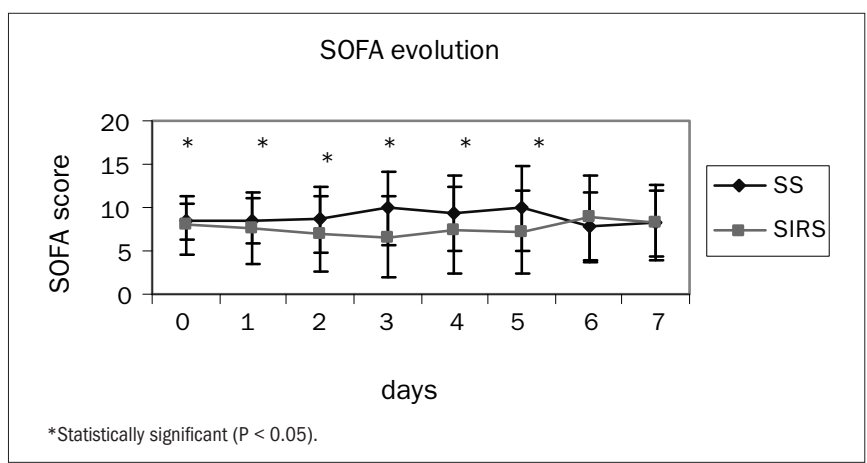

Figure 1. Daily evolution of sequential organ failure assessment (SOFA) score among the SS (septic shock) and SIRS (systemic inflammatory response syndrome) groups.

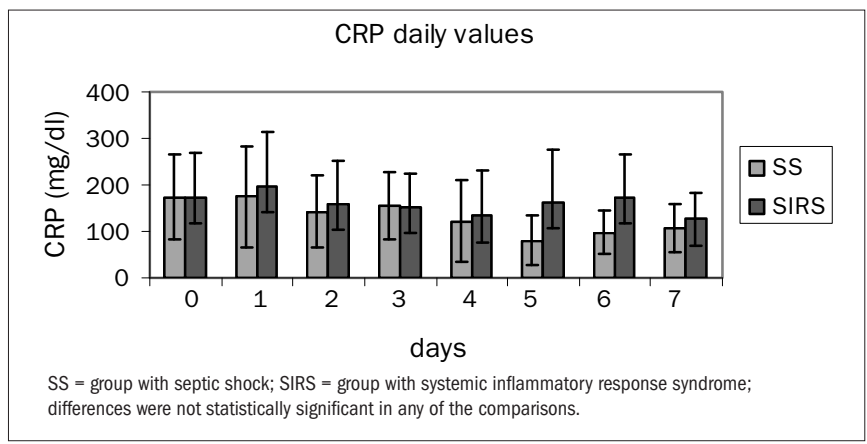

Figure 2. Mean C-reactive protein (CRP) measurements in the two groups.

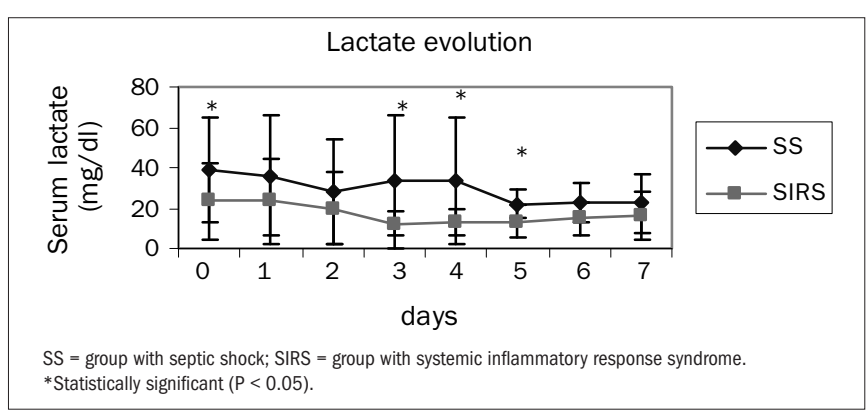

Figure 3. Mean serum lactate measurements in the two groups

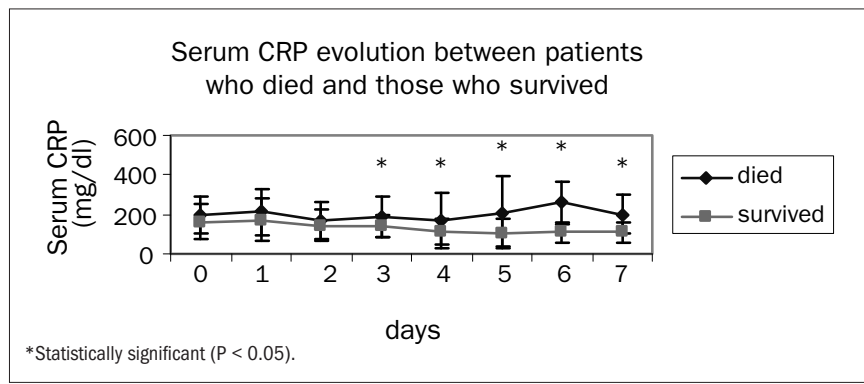

Figure 4. Outcome prognosis according to C-reactive protein (CRP) levels. 
The present study had some limitations. The diagnosis of infection was based on the presence of positive cultures from blood, urine, catheter or tracheal secretion, or on the presence of a presumed focus of infection in the surgical site. It is known that false-negative cultures are a frequent finding among critically ill patients. Thus, some septic patients may be misdiagnosed as presenting SIRS, instead of sepsis. In order to minimize this source of error, patients diagnosed with SIRS who presented any positive culture during the seven-day observation period were excluded.

\section{CONCLUSION}

CRP is not a good predictor for infection among patients presenting septic shock during the early postoperative period.

\section{REFERENCES}

1. Cicarelli DD, Benseñor FE, Vieira JE. Effects of single dose of dexamethasone on patients with systemic inflammatory response. Sao Paulo Med J. 2006;124(2):90-5.

2. Luzzani A, Polati E, Dorizzi R, Rungatscher A, Pavan R, Merlini A. Comparison of procalcitonin and C-reactive protein as markers of sepsis. Crit Care Med. 2003;31(6):1737-41.

3. Enguix A, Rey C, Concha A, Medina A, Coto D, Diéguez MA. Comparison of procalcitonin with C-reactive protein and serum amyloid for the early diagnosis of bacterial sepsis in critically ill neonates and children. Intensive Care Med. 2001;27(1):211-5.

4. Cicarelli LM, Perroni AG, Zugaib M, de Albuquerque PB, Campa A. Maternal and cord blood levels of serum amyloid A, C-reactive protein, tumor necrosis factor-alpha, interleukin-1beta, and interleukin-8 during and after delivery. Mediators Inflamm. 2005;2005(2):96-100

5. Castelli GP, Pognani C, Cita M, Stuani A, Sgarbi L, Paladini R. Procalcitonin, C-reactive protein, white blood cells and SOFA score in ICU: diagnosis and monitoring of sepsis. Minerva Anestesiol. 2006;72(1-2):69-80.

6. Meisner M, Tschaikowsky K, Hutzler A, Schick C, Schüttler J. Postoperative plasma concentrations of procalcitonin after different types of surgery. Intensive Care Med. 1998;24(7):680-4.

7. Levy MM, Fink MP, Marshall JC, et al. 2001 SCCM/ESICM/ACCP/ATS/SIS International Sepsis Definitions Conference. Intensive Care Med. 2003;29(4):530-8.

8. Reade MC, Young JD. Consent for observational studies in critical care: time to open Pandora's Box. Anaesthesia. 2003;58(1):1-3.

9. Reny JL, Vuagnat A, Ract C, Benoit MO, Safar M, Fagon JY. Diagnosis and follow-up of infections in intensive care patients: value of $\mathrm{C}$-reactive protein compared with other clinical and biological variables. Crit Care Med. 2002;30(3):529-35.
10. Lobo SM, Lobo FR, Bota DP, et al. C-reactive protein levels correlate with mortality and organ failure in critically ill patients. Chest. 2003;123(6):2043-9.

11. Marshall JC, Vincent JL, Fink MP, et al. Measures, markers, and mediators: toward a staging system for clinical sepsis. A report of the Fifth Toronto Sepsis Roundtable, Toronto, Ontario, Canada, October 25-26, 2000. Crit Care Med. 2003;31(5):1560-7.

12. Hulley SB, Cummings SR. Designing clinical research: an epidemiologic approach. $1^{\text {st }}$ ed Philadelphia: Williams \& Wilkins; 1988.

13. Okino AM, Bürger C, Cardoso JR, Lavado EL, Lotufo PA, Campa A. The acute-phase proteins serum amyloid $A$ and $C$ reactive protein in transudates and exudates. Mediators Inflamm. 2006;2006(1);47297.

14. Kosuge M, Ebina T, Ishikawa $T$, et al. Serum amyloid $A$ is a better predictor of clinical outcomes than C-reactive protein in non-ST-segment elevation acute coronary syndromes. Circ J. 2007;71(2):186-90.

15. Suprin E, Camus C, Gacouin A, et al. Procalcitonin: a valuable indicator of infection in a medical ICU? Intensive Care Med. 2000;26(9):1232-8.

16. Gabay C, Kushner I. Acute-phase proteins and other systemic responses to inflammation. N Engl J Med. 1999;340(6):448-54.

17. Ugarte H, Silva E, Mercan D, De Mendonça A, Vincent JL. Procalcitonin used as a marker of infection in the intensive care unit. Crit Care Med. 1999;27(3):498-504.

18. Ventetuolo CE, Levy MM. Biomarkers: diagnosis and risk assessment in sepsis. Clin Chest Med. 2008;29(4):591-603, vii.

19. Castelli GP, Pognani C, Meisner M, Stuani A, Bellomi D, Sgarbi L. Procalcitonin and C-reactive protein during systemic inflammatory response syndrome, sepsis and organ dysfunction. Crit Care. 2004;8(4):R234-42.

20. Cicarelli DD, Vieira JE, Benseñor FE. Comparison of C-reactive protein and serum amyloid a protein in septic shock patients. Mediators Inflamm. 2008;2008:631414.

Conflict of interest: Not declared

Sources of funding: Not declared

Date of first submission: March 26, 2009

Last received: August 12, 2009

Accepted: December 10, 2009

Address for correspondence:

Domingos Dias Cicarelli

Divisão de Anestesia do Instituto Central do Hospital das Clínicas

Av. Dr. Enéas de Carvalho Aguiar, 255 - 8o andar

Cerqueira César - São Paulo (SP) - Brasil

CEP 05403-900

Tel. (+55 11) 3069-6365

Fax. (+55 11) 22750569

E-mail: dcicarelli@uol.com.br 